\title{
The transfer of knowledge and the problems of identity in a managed and online context
}

\author{
Inge Hermanrud \\ Hedmark University College, Rena \\ Nordland University, Bodø \\ Email: inge.hermanrud@hihm.no
}

\begin{abstract}
The purpose of this article is to look into the social aspect of learning, and in particular how the construction of identity influences the transfer of knowledge in a managed and online context. The relationship between the 'old-timer' and the 'newcomer' is given special consideration through a qualitative study of the Norwegian Labour Inspection Authority. The study shows that inspectors construct their identity and categorize others in a way that creates barriers to the transfer of knowledge, constructions that are influenced by managerial participation. This article contributes to our understanding of how social aspects influence the transfer of knowledge between old-timers and newcomers in a managed and online context.
\end{abstract}

Keywords: managed networks, communities of practice, knowledge transfer, identity construction, public inspectorate, online context

\section{Introduction}

This article illustrates how the construction of conflicting identities creates problems for the transfer of knowledge between dispersed old-timers and newcomers in a managed and online context. Two central concepts that this 
issue relates to are 'managed networks' and 'communities of practice'. Managed networks are formally initiated arrangements that organizations use to try to exploit the advantages of communities of practice (Lave \& Wenger, 1991; Wenger, 1998) in order to enhance organizational learning. Communities of practice are groups of people who regard themselves as practitioners in the same area of work and therefore share an interest in the same knowledge, since they conduct the same tasks (Wenger, 1998). This article seeks to increase the understanding of managed networks for the sharing of knowledge. Specifically, I contribute to the management of communities of practice by describing the managerial dilemma in relation to the construction of identity.

This study focuses on experiences of the implementation of networks of competence in the Norwegian Labour Inspection Authority (NLIA). Historically NLIA recruited its employees on the basis of their years of experience from branches like building and construction. Newcomers were assigned to an experienced employee and therefore the process of becoming an experienced inspector was the mode of learning. In their respective districts the employees had to conduct inspections regarding different areas of health and safety, ranging from the prevention of accidents to psychological well-being. During the last years this has changed: NLIA now expects the employees to be more specialized professionals who to be assigned both to projects (where the production takes place) and to managed networks of competence (where organizational learning is supposed to take place).

In general, managed networks sometimes overlap with existing communities of practice and serve to enhance current identities and learning practices. Some managed networks are attempts by the organizations themselves as a means of developing new communities of practice (Newell, Robertson, Scarborough \& Swan, 2009). While social identity is a core concept in the literature on communities of practice (Brown \& Duguid, 1991; Lave \& Wenger, 1991; Wenger, 1998), problems of identity have often been underestimated (Hong \& Fiona, 2009). The research concerning managerial efforts to oversee the communities in and between organizations is also in its early stages (Newell et al., 2009). One issue that requires further study is the problem of the use of communities of practice as a proxy for situated learning for presentday heterogeneous workspaces (Macpherson \& Clarke, 2009). Because situated learning takes place in the same context in which is it is applied, heterogeneous workspaces might limit the value of sharing knowledge, since the experiences are generated and interpreted in different contexts.

In this article, I address this gap in the literature by examining networks of competence established by management, and how the members of these managed networks struggle to transfer knowledge among themselves. In particular the relationship between 'newcomers' and 'old-timers' is investigated. The central problem I consider is the constructions of identity that create barriers to the transfer of knowledge in designed organizational learning processes. In particular I discuss how a managed and online context contributes to identity-construction problems. This is an interesting issue because research on networks of practice (Brown \& Duguid, 1991; Brown \& Duguid, 2000) and communities of practice (Lave \& Wenger, 1991; Wenger, 1998) suggests that different forms of constructions of identity might be related to the cultivation of and access to resources of knowledge. A relatively new aspect of this phenomenon is the managerial ambition to integrate 
geographically spread units into one integrated unit by using Information and communication technology (ICT) and networks aiming to develop communication, collaboration, and learning horizontally in the organization (Newell et al., 2009). This study has examined an instance of this development.

This article is structured as follows. First, the concept of the transfer of knowledge and the trade-off between old-timers and newcomers is elaborated. Secondly, the role of identity-construction in the transfer of knowledge is defined and the role of managed and online context is discussed. Thirdly, the research setting and research method and analysis of the study are explained, the multidisciplinary context is emphasized here, which only a few studies on learning across communities of practice has addressed (Oborn \& Dawson, 2010), followed by the empirical section of this article. Finally, findings are discussed and concluding remarks articulated.

\section{Theoretical framework}

\section{The transfer of knowledge and the trade-off between old-timers and newcomers}

Carlile (2004) has developed a useful framework for reflecting upon the management of the transfer of knowledge when the participants have not yet formed a homogenous community. This framework identifies three types of circumstances. The first type describes a continuum with, on one end, a situation where differences and dependencies are known and, on the other, unfamiliarity generates a less clear situation. The second covers those circumstances when there are different interpretations of the same experience (or other types of knowledge). The third occurs when different interests regarding what knowledge is are generated.

In the first circumstance a common lexicon is needed for the transfer of knowledge; in the second, a common meaning has to be developed; and in the third, a common interest must be developed - all to ensure the sharing and assessing of knowledge. Østerlund and Carlile (2005) suggest that newcomers and old-timers have different interests at stake in the sharing of knowledge. There are power issues related to the identification and ownership of meaning, and tensions between canonical and non-canonical practices. Viewed from a practice-based perspective, the transfer of knowledge is simultaneously the transformation of work practice (Gherardi \& Nicolini, 2000), since the transfer of knowledge implies that it transforms what you do, your interpretations and interests, and at the same time how you view yourself and others.

March (1991) suggests that the turnover of personnel between old-timers and newcomers in organizations produces a trade-off in the distribution of knowledge. Experienced members on average know more, but what they know is made redundant by the knowledge already reflected in the organizational code, and they are less likely to contribute new knowledge. On the other hand, new recruits are less knowledgeable (i.e., less experienced in this organizational context) than the individuals they replace, but what they know is less redundant in respect of the organizational code, and they are 
more likely to deviate from it. According to March, old-timers induce exploitation, that is, production, efficiency, and implementation. Newcomers, on the other hand, increase exploration, namely, search, discovery, and innovation. Exploitation and exploration are about negotiating the experiencebased 'best practices' and developing new practices. Hence, the trade-off between old-timers and newcomers is enabled by constructions of social identity that empower the participants to identify themselves with these negotiated work practices.

\section{The role of the construction of identity in the transfer of knowledge}

Researchers currently make use of the term 'Communities of Practice' to analyse and facilitate the transfer of knowledge in a wide range of organizational environments (Roberts, 2006). The literature on communities of practice offers a mutually constitutive account of social identity and the transfer of knowledge. Learning is seen as the process of negotiating identity (Jørgensen \& Keller, 2008). Lave and Wenger's (1991) early account of communities of practice is based on apprentice styles of learning, a theory of newcomer learning whereby novices or newcomers acquire knowledge and skills through interaction with experienced members. Thus the process of gaining competence and membership in a community is linked to changing identities, involving newcomers gradually taking on more expert roles or 'identities of mastery', as Lave and Wenger denote it. In communities of practice a shared sense of identity is seen as an enabler for the transformation of identity and an outcome of the transfer of knowledge (Wenger, 1998). Wenger (p. 149) argues that identity is characterized as:

- Being a negotiated experience;

- Established through membership of the community;

- Connected to our learning trajectory; and

- Reconciling our memberships in different communities

Negotiating experience contributes to the broadening of meaning and the development of identity. Lave and Wenger (1991) view learning as the process of becoming a member of a specific community through participation, and Wenger (1998) refers to the unique history of the individual who has multiple memberships and identifies with different communities of practice, and takes part in different learning trajectories. As Wenger explains:

... we all belong to many communities of practice: some past, some current; some as full members, some in more peripheral ways. Some may be central to our identities while others are more incidental. Whatever their nature, all these various forms of participation contribute in some way to the production of our identities. (1998, p. 158)

Hence, the construction of identity with respect to the transfer of knowledge has been described in two ways. One view is that it is a one-way, linear process, the movement from apprentice to master, like becoming a tailor or butcher (Lave \& Wenger, 1991). The other view is that the construction of identity is a dual process, involving the belonging and positioning in a discourse in negotiations, where the development of a new identity helps in accountability to others in the same activity (Wenger, 1998). 
In the organizational context, social categorizations regarding being a member of the organization or sub-groups, or both, produce prototype-based depersonalizations of self and others responsible for the social identities in organizations (Hogg \& Terry, 2000). Social-identity theories focus on how social categorizations and participation in groups form who you are. Newcomers enter the organization with one social identity which will influence their learning and their construction of other social identities. Social identities can, therefore, both enable and constrain the transfer of knowledge between newcomers and old-timers.

In the literature on identity in organizations there are two competing views regarding the role of social identity. The integrationist view emphasizes the coherent characteristics of organizations, stressing that the transfer of knowledge can be supported by the development of organizational identity, through trust, loyalty, and shared values and implicit norms, for example (Willem, Scarborough \& Bulens, 2008). This integrationist view proposes a positive relationship between organizational identity and the transfer of knowledge (Haslam, Postmes \& Ellemers, 2003; Kane, Argot \& Levine, 2005). In this view, through the de-personalization in social identity, spontaneous and unconditional willingness to transfer knowledge and transformation of practice can occur. The fragmentationalist view, in contrast, regards social identities as being multiple and fragmented, and are thus more unpredictable (Albert, Ashforth \& Dutton, 2000; Alvesson, 2000; Willem et al., 2008). Willem et al. (2008, p. 374) identify three scenarios for forms of social-identity construction in organizations:

1) There is a dominant company-wide social identity, without or with a weak sub-group social identity;

2) There are multiple social identities, different social identities in each unit or community of practice, and possibly coexisting with a non-dominant company-wide identity.

3) Organizational members do not primarily identify with the organization or sub-groups, but with external groups, such as professional associations.

It is interesting to note that the employees, both newcomers and old-timers in scenarios 2 and 3 , do not need to identify with the organization at all. This gives us a complex, less straightforward, and less optimistic answer to the positive role of 'managed' identity-construction in the transfer of knowledge between old-timers and newcomers in managed networks.

\section{The role of managed and online contexts for the construction of identity and the transfer of knowledge}

The establishment of managed networks supported with ICT is an intervention by the organization to constitute the necessary conditions for their employees to connect and transfer knowledge. Regarding the content, some researchers advise that management should support peer-to-peer-based learning methods instead of classrooms, and avoid privileged and formally objectified knowledge, because it neglects the tacit practice-based knowledge and allows the participants to decide and control which components of knowledge are important to them (Hislop, 2009). 
Managed networks for the transfer of knowledge imply two contradictory managerial roles. Managerial interventions are sometimes required because organizations primarily use these networks to integrate dispersed knowledge, which reflects organizational value. Distributed networks require also some form of managerial control because the members are dispersed, which makes social learning less likely to take place than in a community of practice, whose members are typically co-located. Then again, the literature describes networks and communities of practice as being strongly emergent in nature, self-organizing, informal, and free from influence from management, or even negatively influenced by interventions by management. Managerial control will, therefore, likely frustrate members' desire to share their geographically dispersed practice-related knowledge (Agterberg, Hoof, Huysman \& Soekijad, 2010; Alvesson, Kärreman, \& Swan, 2002; Thompson, 2005;).

It is widely accepted in the literature on virtual communities of practice that ICT is not a perfect substitute for face-to-face encounters or meetings and most virtual communities of practice need some face-to-face time to be most effective (Dubé, Bourhis \& Jacob, 2006). Deprived of an abundance of face-toface contacts, especially at the beginning, virtual communities of practice may have problems or take longer to establish a sense of identity, or both (Cramton, 2001; Dubé et al., 2006). There can be several explanations for these challenges. On the personal level, identification with others can be related to those who are helpful and those who are not. In face-to-face settings, reciprocity appears to be critical for sustaining supportive relationships and collective action (Putnam, 1995). On the other hand, in electronic networks of practice - web-based forums in which anyone can access and participate (Wasko \& Faraj, 2005) - findings have shown that the norm of reciprocity is not a significant predictor for helpfulness of knowledge contribution. Wasko and Faraj's explanation is that online-based interactions may be generalized rather than dyadic, and direct reciprocity is not necessary for sustaining collective action. At the level of community Amin and Roberts (2008) point out that benefits of online communication in knowledge-transfer processes are higher for professional communities (whereby you become a clinician through individual academic study, teamwork, and virtual interaction) than communities of task or craft (whereby you become a midwife, tailor or flute maker through apprenticeship in a close-knit, face-to-face community), since once individuals have mastered a body of professional knowledge, they appear to benefit from exchanges of knowledge facilitated by online communications with dispersed members of their profession. Their explanation is that the presence of professional standards and identity ensures the circulation of knowledge.

\section{Methodology}

\section{Research setting}

The NLIA has undergone a process of organizational change, from a hierarchical rule-based bureaucracy towards a more professional, knowledgebased bureaucracy (Mintzberg, 1983). The organization has also moved towards a heterarchy, relying increasingly on collaboration and cooperation and making it a more decentralized network-based organization. One can 
argue that the NLIA is a hybrid organization, consisting of the following coexisting elements: user-oriented logic (we inspectors know how to help the business), control-oriented logic (we inspectors know the legislation), and emerging professional logic (we inspectors know when stress is unacceptable).

The NLIA is a geographically distributed public organization, with employees dispersed around the country. The inspectors conduct inspections of the use and storage of chemicals, installed ventilation facilities, measures taken to prevent accidents at work or psycho-social well-being at work, or some or all of these. Some work within one area (like occupational hygiene or the psychosocial well-being at work). Others (in particular, inspectors in remote areas) have to conduct many different kinds of inspections. The inspectors in this organization have a range of backgrounds. Historically speaking, people with years of experience have been recruited from industries in the building and construction sectors. Others moved up from working as clerks to becoming inspectors, often after gaining college qualifications. More recently, people have entered the organization with a fuller and more extensive professional college degree or a university degree (bachelor's or master's).

While the NLIA used to keep its experts at its central core, it now has to develop their expertise in different regions, among the geographically dispersed inspectors. These people are now expected to be collective experts, experts for their region, but not national experts. Attempts have been made to achieve this aim by setting up the networks of competence among inspectors. The networks of competence are managed networks, aimed to promote the sharing and learning of knowledge in the organization. The name of these networks has been debated. Some argue that these networks are not 'networks of competence', as management labels them, but 'professional networks', stressing the development of academic knowledge within the networks. Others use the broader concept of a 'network of competence', emphasizing the mix of professional and experience-based knowledge which needs to be developed. The inspectors within each region are assigned to one of four different networks, usually on the basis of their professional orientation or area of interest.

The geographical distance between the different members can be as much as $1300 \mathrm{~km}$, and, owing to their limited budget, they may only see each other face-to-face twice a year for two days at a time. The sharing and learning of knowledge are therefore supposed to take place via the use of ICT. The networks meet up around once a month for one to two hours. The tool used in the network setting is GoToMeeting ${ }^{\mathrm{TM}}$, a highly rated web-based tool that allows everyone in a group meeting to share whatever is on their computers (Lipschutz, 2007). This tool contains features that enable screen, keyboard, and mouse sharing, as well as web chat and telephone conversations. It is also integrated with email and an Outlook ${ }^{\mathrm{TM}}$ calendar to allow meetings to be booked effectively (see http://www.gotomeeting.com). While they are able to share everything they have on their computers and engage in meetings over the telephone, the participants do not actually see each other. At face-to-face meetings, which take place once or twice a year, they visit a business as a group and discuss what they have experienced there. Or they invite an external expert lecturer or practitioner to give a talk on a particular topic. 


\section{Sampling procedure}

This study involves data from five networks of competence: two networks set up for the prevention of accidents, one for occupational hygiene and two within the area of psychological well-being. All of the networks were staffed with around eight to 14 people. The networks were selected on the basis of the following criteria: they all offered a distributed context (as they were networks from the two largest regions), and they represented different areas of knowledge, thereby adding variation to the study. In the two networks of psychological and social well-being there were no psychologists, but instead people with degrees in human geography and sociology, priests, former police constables, social workers, and others. The two networks for the prevention of accidents were staffed with both engineers and social scientists. The most homogeneous network was the network for occupational hygiene, in which at the time of the study nearly all of the participants had some type of degree in engineering. All of the networks, as well as the inspectors, included one or two lawyers. This study therefore represents a context including multiple preexisting identities. Since the networks of competence had not been functioning very well, one manager had taken part in the discussions to ensure that everybody was polite and respectful, and to encourage further participation through acknowledging the importance of their attendance.

\section{The collection and analysis of data}

The collection of data took place over a three-year period. This involved interviewing network members and managers in the organization, as well as observing physical and online meetings and documents (see table 1 for an overview). I sought the data from multiple members, newcomers and oldtimers, inspectors and managers, from different networks, figuring that they could provide different insights into my topic. I was logged in to the same meetings as the participants, with access to what was happening via the telephone and the computer. Sometimes, at the end of the meetings, when the participants were making evaluations, I asked questions regarding what had taken place.

Table 1. The methods of collecting data in this study.

\begin{tabular}{ll}
\hline Interviews & $\begin{array}{l}18 \text { individual interviews } \\
\text { One group interview of five managers } \\
\text { Questions asked during observations }\end{array}$ \\
Observations & $\begin{array}{l}2.5 \text { years of observation of face-to-face } \\
\text { and online meetings in two networks }\end{array}$ \\
Archival material & $\begin{array}{l}\text { Agendas of meetings } \\
\text { Minutes of meetings } \\
\text { Official evaluation }\end{array}$ \\
\hline
\end{tabular}

This study defined newcomers as participants in the networks of competence with work experience of less than seven years in the organization. Among the 18 interviewed I had four informants with less than three years of experience, four with four to seven years' experience and ten with seven up to 30 years of experience in the Authority. 
The individual interviews lasted between 45 minutes and two hours. The group interview lasted for two hours. Owing to the long distances I had to travel, nine of the 18 individual interviews were conducted via telephone. Although telephone interviews are thought to be the second-best option for obtaining data in situations where social cues are important (Opdenakker, 2006), the telephone interviews proved to be just as elaborative as the ones conducted face-to-face. One reason for this may have been the informants' familiarity with presenting and elaborating on complex matters via the telephone.

All of the interviews were recorded, transcribed and analysed by the use of the NVivo 8.0 tool. The interviews were coded around sensitizing concepts (Blumer, 1954; Hoonaard, 1997), such as 'newcomer perception', 'old-timer perception', 'negotiations', and 'identity'. In the axial coding I devised the categories of 'givers' and 'receivers' and 'negotiating identity' and 'role of manager' and 'online environment'. In this final stage, notes from observations and archival data were used to develop the categories further.

\section{Findings}

The overall findings indicate that there are problems in the relationship between newcomers and old-timers situated in the managed-network context. I shall report and discuss my detailed findings in the following sections.

\section{How newcomers and old-timers perceive each other in the context of networks of competence}

Judging from the viewpoints of the newcomers and the old-timers (Table 2), we can see that it is evident that both parties were constructing sub-identities. The findings also suggest that the NLIA was lacking a strong organizationalwide identity which could provide the spontaneity and willingness to transfer knowledge from old-timers to newcomers. There are also differences in inward and outward orientations between newcomers and old-timers, respectively. This I have already reviewed in my second interview in this study. One oldtimer put it in this way: 'Many of the inspectors are not interested in what's going on in the organization at all; they spend their time out in the field inspecting'. Newcomers, on the one hand, are eager to learn about their organization, but the old-timers spend more time interacting with others in the field than they do with their colleagues in the organization. While the newcomers regarded the networks as an opportunity to learn about their organization and to nurture their professionalism, many old-timers regarded the networks as a scheme which does not work for them. These contrasting images have created tensions and a lack of engagement (e.g., no-shows at meetings). 
Table 2. Conflicts of identity between newcomers and old-timers in networks of competence in the NLIA

Newcomers' perceptions

We are becoming specialized experts.

'For the NLIA, it is very important that we have people with in-depth expertise and professional expertise in different fields, nurtured by activities in the networks.' (male inspector, three years of experience at the NLIA)

We think that the network is a good idea.

'I think the intention behind it is very good, as we need a place where we can get professional input.'

(female lawyer, one year of experience at the NLIA)

We relate to other newcomers.

'I relate, when I have questions, to other young people; I think it is the age dimension'

(female inspector, one year of experience at the NLIA.)

I am often alone with my questions in my office.

'I miss having somebody to talk to, as there are only two of us at my office, and the other one is a lawyer.'

(female inspector, one year of experience at the NLIA)

The old-timers are a problem.

'They are not willing to share their experience.'

(female inspector, one year of experience at the NLIA)
Old-timers' perceptions

We are inspectors, and inspecting is a separate professional field.

'This ... inspection ... is about communication skills ... communication with the managers of the inspected business to ensure that change happens there. But sadly our management doesn't understand that inspection is a separate professional field.'

(male inspector, seven years of experience at the NLIA)

We miss the national experts.

'Now there are a lot more employees in the Labour Inspectorate, and we are divided into networks, and it is not so easy. Previously we had contact with those who were specialists in the Directorate. I would call the expert at the Directorate on the phone, and talk to him directly. We don't have this anymore, and I miss it.'

(male inspector, more than 30 years of experience at the NLIA)

We use our informal network.

'I know from experience who is a specialist regarding certain types of accidents.'

(male inspector, more than 30 years of experience at the NLIA).

We learn while doing inspections.

'All of the learning takes place when conducting inspections together, in twos.'

(male inspector, more than 20 years of experience at the NLIA)

Newcomers are a problem.

"When "newcomers" enter the network, the discussions are brought back to level one.'

(Norwegian Labour Inspection Authority, 2008 Official Evaluation, p. 10)

\section{The construction of the 'givers' and the 'receivers'}

The inspectors view the exploitation of experience-based knowledge as problematic, as there are members who become 'givers' who always share with others but rarely receive anything in return. The newcomers are the 'receivers', who then benefit from the network. One senior inspector expressed his views in this way: 
[The networks of competence] are most useful for the less experienced members, and less so for the more knowledgeable and experienced. Your role as a giver is larger than that of a receiver.

These networks are supposed to play the role of a collective, to whom individual inspectors can ask questions. It seems to be less useful for those with the highest competences, as reflected upon by this manager, with more than 30 years of experience in the organization:

\begin{abstract}
Many feel that they do not receive as much in the networks ... it seems to me that those with the highest competence get little out of it ... and this is just because they are supposed to give to the others
\end{abstract}

This unbalance has made it difficult to motivate the more competent employees to contribute to the network. For an outsider to this organization it might be obvious that the participants should have expected that the contributions from the older ones would be larger than those of the newcomers. In this organization however, the old-timers compare what they had before the networks of competence, when they had a national expert and an informal network of peers with special expertise to whom they could turn.

\title{
Negotiating identity and the role of the manager
}

What is an inspector in the Labour Inspectorate? As presented in Table 2, the old-timers refer to what they do in the field. They often describe how they work with their clients to instigate real changes in the inspected businesses as communicative or pedagogic skills. At the network meetings information from management is given, inspectors or invited external lecturers conduct academic lectures, and experiences are shared in form of stories and Powerpoint $^{\mathrm{TM}}$ presentations. For example, in the network for occupational hygiene, academic lectures are held on the hazards involved when different chemical substances are stored together, and what might happen and what they should look for when inspecting. Another example is what takes place in meetings in the area of psychological well-being. Here by reviewing research they try to determine what causes stress by and how this can affect individuals in a negative way, and how they can become aware of unhealthy stress when carrying out inspections and writing orders on it. These activities are good examples of how an exploration of implications of academic knowledge and new research can be integrated with existing experiences and inspecting practices.

On the other hand, several of my respondents reported problems. First, the inspectors emphasized differences in professional orientation as a major problem that made it difficult to integrate different areas or perspectives of knowledge. Like when they stressed that the language of some of the other participants in the network was too full of unknown terms. Several of my respondents emphasized that some of these problems were related to the differences between newcomers and old-timers. At a regional meeting, a former district manager, who is now an adviser, voiced an emerging problem:

I think we have encouraged new employees to believe that they should be able to immerse themselves in their field. Companies have now begun to complain that the inspectors are academically strong but that they are difficult to communicate with (notes from a regional meeting). 
This quotation reveals a conflict which exists within the organization regarding knowledge and which path should be followed, for both the individual and the organization. For many of the experienced old-timers, inspections are about engaging in a dialogue with clients and making real changes in the workplace under inspection. Some newcomers, in contrast, have formed another picture, as noted by one inspector: 'The business has hired the best experts; we need to develop the same [expertise] to be able to carry out inspections there' (notes from a regional meeting). To me this reveals two different and conflicting orientations of knowledge: one towards the inspected business from the perspective of finding practical solutions (through communication), and the other towards mobilizing expertise to match the highly competent organizations that offer company health and safety services, which are hired by the inspected business. The latter orientation indicates a movement towards a greater degree of specialization in the NLIA. The networks of competence seem to have participants who advocate competing orientations of knowledge with different learning trajectories and practices.

Secondly, newcomers expressed their frustration about how they sometimes do not know where to go with their questions regarding policy. They asked their managers and colleagues, addressed the problem in the network of competence meetings, and sent letters to the head office of the directorate, and they did not get any answers. Some old-timers, on the other hand, said that they are unwilling to share their experiences or to reveal their practices in the setting of the network of competence because this might result in new formal directives regarding how they should do their work in accordance with policy. Old-timers were also more accustomed to stronger dyadic relationships:

\begin{abstract}
I think the old boys probably do not think that the network is the right venue for learning ... they come from another time ... before the organization was reorganized ... [they] miss [having] one key expert to deal with. They are used to a much stronger personal relationship with the expert. I can understand that they do not have the same trust in a network (newcomer).
\end{abstract}

The expert in this quotation pointed to the time some years back when the inspectors could call an expert at the directorate in Oslo and get answers there. Old-timers, when describing their early days in the inspectorate, also referred to the importance of learning from one experienced inspector and from the national expert. Two old-timer inspectors talked positively about the networks of competence. Both of them had developed ICT skills over the year and seemed to be very out-spoken.

Thirdly, the role of the participating manager is of interest here. Many of my informants said that to have a manager present was very helpful since he or she contributed useful information about the organization and was often very experienced. On the other hand, this study has also revealed another role. One female inspector reflected upon this situation in one meeting when the manager was not present:

Ever since you asked us, I have started to reflect upon it, and I think the manager, through engagement, controls us. The manager reduces the number of perspectives in the discussions, and the discussions end 
earlier compared to when the manager does not participate (notes taken from conversations after a GoToMeeting ${ }^{\mathrm{TM}}$ meeting).

Examples of different perspectives are current policies and rules and the needs of the client or findings in recent research. In one meeting a manager expressed this when discussing whether or not this group should learn about the solutions-oriented approach, and use it as a tool to reflect on their work practices: 'We must not create new uncertainty around the policy... in a way the learning must not give mixed signals regarding our role...'. Learning this framework would promote the role of problem-solver that the Inspectors have often taken. In my interview data some old-timers stressed that this was their role. This manager was not sure, however, that they should adopt this role of helping inspected businesses to solve their problems, and thought that their role should be limited to control. To summarize, I would say that the newcomers relate the transfer of knowledge to a professional field and policy, while the old-timers are more likely to relate it to activities in the field that make a positive impact there by finding workable solutions and by problem-solving in the field.

\section{Discussion}

The newcomers and the old-timers situated in the managed and online network seem to have experienced problems in establishing a common identity, as envisioned in the theory of communities of practice (Wenger, 1998). I can point to several reasons for this situation. There have been a number of organizational changes and there are many new employees in the organization with different backgrounds. They rarely meet face-to-face, they work in different localities and with different clients, and it seems that there are very few strong interpersonal ties between the self-managed, independent, and dispersed inspectors.

Both the social categorization and the construction of identity have taken other paths than ones that could have enhanced a mutual construction of identity and the transfer of knowledge. As a result, these developments have created unclear learning trajectories for the newcomers and problems regarding the negotiation of experience and meaning across old-timers and newcomers.

First, the categorization of each other as 'givers' and 'receivers' is counterproductive in making the old-timers and newcomers accountable to each other in a way that promotes a good balance between exploitation of existing knowledge and exploration of new knowledge (March, 1991). The narratives behind these two social categories communicate an uneven contribution from individuals, reducing the willingness of those who see themselves as 'givers' to contribute. This categorization of self and others reduces the generalized reciprocity and also hampers the development of the sub-group identity and reciprocity which could have been useful for the transfer of knowledge in this context. Since the members do not know when or if they can benefit from the networks of competence, nearly only general norms for reciprocity and loyalty to the organization move them to contribute. In the long run this is not enough to develop the supportive relationships needed for transfers of knowledge. The distinction between the 'givers' and the 'receivers' resembles the distinction between the 'worthy' and the 'unworthy' in other contexts, giving in this context the 'givers' (often experienced old-timers) a legitimate reason to stop contributing, since they get so little out of it. This is an example of a creation of 
a self-identity where non-participation becomes socially acceptable among a group, in this case, the old-timers. This construction resolves tensions among the old-timers regarding what they should do (i.e., organizational norms) and what they are willing to do. It is counter-productive for the transfer of knowledge between newcomers and old-timers, however.

Table 3. Negotiating identities in a context of managed networks

\begin{tabular}{|c|c|c|c|}
\hline $\begin{array}{l}\text { Negotiating } \\
\text { identities }\end{array}$ & Problem & What causes the problem? & Consequences \\
\hline \multirow[t]{3}{*}{$\begin{array}{l}\text { Problems when } \\
\text { negotiating } \\
\text { experience }\end{array}$} & $\begin{array}{l}\text { It is difficult to } \\
\text { integrate different } \\
\text { perspectives. }\end{array}$ & $\begin{array}{l}\text { There are conflicts in the orientation of } \\
\text { knowledge. There are also a lack of a } \\
\text { common lexicon, different interpretations of } \\
\text { the same issue, and interest invested in } \\
\text { practices. }\end{array}$ & $\begin{array}{l}\text { Experiences are } \\
\text { viewed from very } \\
\text { different } \\
\text { perspectives. }\end{array}$ \\
\hline & $\begin{array}{l}\text { The old-timers leave } \\
\text { questions } \\
\text { unanswered. }\end{array}$ & $\begin{array}{l}\text { The old-timers are not able (ICT } \\
\text { environment) or willing (managed } \\
\text { environment), or both, to give an answer to } \\
\text { the newcomers' questions }\end{array}$ & $\begin{array}{l}\text { It is unclear who the } \\
\text { experts are, who } \\
\text { can give an answer } \\
\text { regarding what to } \\
\text { do. It is unclear how } \\
\text { to become an } \\
\text { expert. }\end{array}$ \\
\hline & $\begin{array}{l}\text { Discussions end } \\
\text { early. }\end{array}$ & $\begin{array}{l}\text { Managers actively put an end to discussion } \\
\text { since it might threaten a unified } \\
\text { interpretation of the policy. }\end{array}$ & $\begin{array}{l}\text { It hampers the } \\
\text { negotiation of } \\
\text { experience from } \\
\text { different } \\
\text { perspectives, i.e., } \\
\text { hinders the mutual } \\
\text { construction of } \\
\text { identity. }\end{array}$ \\
\hline
\end{tabular}

Secondly, due to different knowledge orientations and interests, and sometimes due to the role of the manager (Table 3), it is difficult to negotiate experiences towards a mutual understanding, which is, according to Wenger (1998), important in the identity-construction process. The lack of joint tasks and shared responsibilities contributes also to too few opportunities for developing mutual interests of knowledge. The role of management and online context will be discussed more in depth in the following sections.

\section{The role of the managed context for the mutual construction of identity and the transfer of knowledge}

Old-timers and newcomers might have different interests at stake regarding access and control over resources of knowledge (Østerlund \& Carlile, 2005). The old-timers in my study have an interest in conducting their work in a way that is consistent with their own preferences, or, put differently, in the practices of inspection they have invested in. In this context of managed networks of competence, old-timers seek to guard this interest by not disclosing 
everything, since disclosure might turn into new formal rules which could reduce flexibility in the field. The old-timers prefer learning in twos, face-toface, during inspections or on the phone with people they know and trust. Their key asset of knowledge is the experiences and communicative skills they have developed through their relations to their clients, an area of knowledge that they feel is not acknowledged by management (table 2).

Others, often newcomers, put their professional identity in the foreground and are eager to discuss their professional field online as well as face-to-face. Nurturing the professional identity can also be seen as a strategy to avoid managerial control and to increase the inspectors' individual freedom to handle tasks. But it is also an orientation of knowledge that creates many barriers related to language, interpretation, and interest (Carlile, 2004), which influence negatively the negotiation of experience and the mutual construction of identity among the participants.

The old-timers and newcomers are not the only ones with interests at stake in the context of managed networks: the participating manager also has interests. Agterberg et al. (2010) state that online intra-organizational networks of practice require some form of managerial control and support to develop their social learning. My findings similarly suggest that managers contribute positively through their engagement, their experiences or just by their presence. But managers also contribute negatively when their direct involvement cuts short the sharing of experiences and the exploration of new ideas (table 3). When the manager states that the inspector role is 'only' control, the manager also denies the participants the discretion to decide what aspect of knowledge is important in their practice. This relives the dilemma: on the one hand, managers are supposed to focus their employees towards organizational goals and to end debates, one the other hand, much of the tacit knowledge here is embedded in a user-oriented role. Management hesitates to acknowledge this user-orientated role, but it is a core component of the oldtimers' practice, identity, and knowledge. The exploitation of existing practice threatens the fragile 'impression' of consensus around the interpretation of the existing policy, and this threatens managers' ability to control their employees and to implement policy effectively.

When all three groups - newcomers, old-timers and managers - have these different interests at stake, it is hard to negotiate freely and to develop the mutual identity needed to enhance the transfer of knowledge among the participants. These findings support the idea that learning processes can be assisted, but also that interventions by management negatively influence them (Agterberg et al., 2010; Alvesson et al., 2002; Thompson, 2005). When writing about managing communities, Newell et al. (2009) emphasize that they only can be successful if managers limit their tendency to control and find new ways of managing, like supporting new expert roles, creating events, and documenting work practices. The management should, therefore, be more thoroughly informed about how the inspectors actually work if a managed transfer of knowledge is to succeed. One way forward could be for managers to support and acknowledge the user-oriented practices and knowledge, and to promote the roles of the old-timers as experts in order to motivate the transfer of knowledge from old-timers to the newcomers. 


\section{The role of online relations for the construction of identity and the transfer of knowledge}

The online encounters in these managed networks of competence do not seem to be supported by the same generalized reciprocity, which, according to Wasko and Faraj (2005), facilitates collective action in the case of electronic networks of practice (web forums). Instead it seems that the transfer of knowledge across the inspectors is more dependent on direct reciprocity, which is difficult to develop in this group-oriented online environment. In my findings I can see several reasons for this situation:

1) There are too many participants in the GoToMeeting ${ }^{\mathrm{TM}}$ meetings, as many as 15 , and many are silent.

2) The participants do not see each other (GoToMeeting ${ }^{\mathrm{TM}}$ ), and it is difficult to get to know each other.

3) The old-timers were used to a dyadic relationship with a 'master' (when they were newcomers) and a national expert (later on) when learning.

The third reason implies an interesting finding in relation to the role of reciprocity in these managed networks. Maybe the reason why the experienced old-timer creates problems is due to his or her familiarity with dyadic relations rather than the generalized types of reciprocity a managed network can provide. When the old-timer reminisces, he or she looks back on a master-apprentice relationship and a strong association with an expert at the directorate. Offering and receiving generalized reciprocity by a larger managed network seems to be an unfamiliar source for the transfer of knowledge for these dispersed inspectors. This offers a complementary explanation besides the role of professional standards (Amin \& Roberts, 2008) regarding why online communication in knowledge-transfer processes is easier for professional communities than this task or craft community that these veteran inspectors seem to belong to. The old-timers appear to represent a task community where dyadic relationships are important - in contrast to the more academically oriented newcomers who rely on other newcomers or groups of the same profession.

\section{Conclusion}

For more than two decades, learning theorists have studied the social aspects of the transfer of knowledge. The literature on communities of practice regard the forms of constructions of identity as being related to the cultivation of, and access to, resources of knowledge. Novices learn from masters and are becoming central members in the community (Lave \& Wenger, 1991; Wenger, 1998). However, I have found that the newcomers and old-timers in this managed and online network context often do not regard each other as peers who possess useful knowledge and practices. The role of managed and online context contributes to complementary explanations for why they struggle to construct a mutual identity that facilitates the transfer of knowledge.

While managerial intervention is needed to integrate dispersed knowledge (Newell et al., 2009), and more is required in online contexts (Agterberg et al., 2010), it also creates problems of identity. My study reveals that the 
negotiations of experience and the broadening of meaning, that is, the mutual construction of identity and the transfer of knowledge between newcomers and old-timers, is hampered by a lack of willingness or ability to share and by managers who control what knowledge is. On the other hand, there is need for some managerial effort to formulate goals for the networks of competence and to negotiate and communicate with and to motivate the members.

I also suggest that online communication is easier for professional communities than it is for this task or craft community that the old-timers appear to belong to, not only due to a lack of shared professional standards (Amin \& Roberts, 2008), but also due to a lack of familiarity with generalized reciprocity among the old-timers. Further studies should look into whether veterans and more academically oriented newcomers in present organizations rely on different forms of reciprocity. If old-timers in craft- or task-based communities in general mostly rely on dyadic relationships, and the aim is to transfer knowledge to more academically oriented newcomers and vice versa, managers should promote dyadic relationships in addition to networks in order to promote the mutual construction of identity for the transfer of knowledge.

\section{Acknowledgements}

An earlier version of this paper was presented at the 2011 international conference for Organizational Learning, Knowledge and Capabilities (OLKC), at Hull University Business School. The author would like to thank Editor Steven Connolley and the two anonymous referees of the Nordic Journal Social Research for their helpful comments and suggestions on further drafts of this manuscript.

\section{References}

Agterberg, M., Van den Hooff, B., Huysman, M. \& Soekijad, M. (2010). Keeping the wheels turning: The dynamics of managing networks of practice. Journal of Management Studies, 47(1), 85-108.

Albert, S., Ashforth B.E. \& Dutton, J.E. (2000). Organizational identity and identification: charting new waters and building new bridges. Academy of Management Review, 25(1), 13-17.

Alvesson, M. (2000). Social identity and the problem of loyalty in knowledge-intensive companies. Journal of Management Studies, 37(8), 1107-1123.

Alvesson, M., Kärreman, D. and Swan, J. (2002). Departures from knowledge and/or management in knowledge management. Management Communication Quarterly, 16(2), 282-91.

Amin, A. \& Roberts, J. (2008). Knowing in action: beyond communities of practice. Research Policy, 37, 353-369.

Blumer, H. (1954). What is wrong with social theory? American Sociological Review, 18(1), 3-10. 
Brown, J. S. \& Duguid, P. (1991). Organizational learning and communities of practice: Toward a unified view of working, learning, and innovation. Knowledge and Communities, 2(1), 40-57.

Brown, J. S. \& Duguid, P. (2000). The social life of information. Boston Mass: Harvard Business School Press.

Carlile, P. R. (2004). Transferring, translating and transforming: An integrative framework for managing knowledge across boundaries. Organization Science, 15(5), 558-568.

Cramton, C. D. (2001). The mutual knowledge problem and its consequences for dispersed collaboration. Organization Science, 12(3), 346-371.

Dubé, L., Bourhis, A. \& Jacob, R. (2006). Towards a typology of virtual communities of practice. Interdisciplinary Journal of Information, Knowledge, and Management, 1, 69-93.

Gherardi, S \& Nicolini, D. (2000) To Transfer is Transform: The Circulation of Safety Knowledge. Organization. 7(2): 329-348.

Haslam, S.A, Postmes, T. \& Ellemers, N. (2003). More than a metaphor: organizational identity makes organizational life possible. British Journal of Management, 14(4), 357-369.

Hislop, D. (2009). Knowledge management in organizations: A critical introduction. Oxford: Oxford University Press.

Hogg, M. A. \& Terry, D. J. (2000). Social identity and self-categorization processes in organizational contexts. Academy of Management Review, 25(1), 121-140.

Hong, J. F. L. \& Fiona, K. (2009). Conflicting identities and power between communities of practice: The case of IT outsourcing. Management Learning, 40(3), 311-326.

Hoonaard, W.C.v.d. (1997). Working with sensitizing concepts: analytical field research. Thousand Oaks, California. Sage.

Jørgensen, K.M., \& Keller, H.D., (2008). The Contribution of Communities of Practice to Human Resource Development: Learning as Negotiating Identity. Advances in Developing Human Resources, 10(4), 525-540.

Kane, A.A., Argot, L. \& Levine, J.M. (2005). Knowledge transfer between groups via personnel rotation: effects of social identity and knowledge quality, Organizational Behavior and Human Decision Processes, 96(1), 56-71.

Lave, J. \& Wenger, E. (1991). Situated learning: Legitimate peripheral participation. Cambridge: Cambridge University Press.

Lipschutz, R. P. (2007). GoToMeeting 3.0 review. Retrieved on 20 November 2011 from http://www.pcmag.com/article2/0.2817.2154128,00.asp.

Macpherson, B. \& Clark, A. (2009). Islands of practice: Conflict and a lack of 'community' in situated learning. Management Learning, 40(5), 551-568.

March, J. G. (1991). Exploration and exploitation in organizational learning. Organization Science, 2(1), 71-87.

Mintzberg, H. (1983). Structure in fives: Designing effective organizations. Engelwood Cliffs, NJ: Prentice Hall.

Newell, S., Robertson, M., Scarborough, H. \& Swan, J. (2009). Managing knowledge work and innovation. Hampshire: Palgrave Macmillan. 
Norwegian Labour Inspection Authority. (2008). Evalueringsrapport. Etatens kompetansenettverksarbeid. [Evaluation. The Authority's work with networks of competence]. Trondheim: Avdeling for organisasjon. Direktoratet for Arbeidstilsynet.

Oborn, E., \& Dawson, S. (2010). Learning across Communities of Practice: An Examination of Multidisiplinary Work. British Journal of Management,. 21(4), 843-858.

Opdenakker, R. (2006). Advantages and disadvantages of four interview techniques in qualitative research. Forum: Qualitative Social Research, 7(4), Article 11.

Putnam, R. (1995). Tuning in, tuning out: The strange disappearance of social capital America. PS: Political Science and Politics. 28(4)., 664-683.

Roberts, J. (2006). Limits to communities of practice. Journal of Management Studies, 43(3), 623-639.

Thompson, M. (2005). Structural and epistemic parameters in communities of practice. Organization Science, 16(2) 155-64.

Wasko, M. M. \& Faraj, S. (2005). Why should I share? Examining social capital and knowledge contribution in electronic networks of practice. MIS Quarterly 29(1),, 36-67.

Wenger, E. (1998). Communities of practice: Learning, meaning and identity. New York: Cambridge University Press.

Willem, A., Scarborough, H. \& Bulens, M. (2008). Impact of coherent versus multiple identities on knowledge integration. Journal of Information Science, 34(3) 370386.

Østerlund, C \& Paul, C (2005). Relations in Practice: Sorting Through Practice Theories on Knowledge Sharing in Complex Organizations. The Information Society, 21(2), 91-107. 